\title{
Leadership in times of crisis
}

\author{
Bandar AlKnawy
}

Chief Executive Officer, Health Affairs, Ministry of National Guard President, King Saud Bin Abdulaziz University for Health Sciences, Riyadh, Saudi Arabia

\section{Correspondence to}

Dr Bandar AlKnawy, King Saud Bin Abdulaziz University for Health Sciences, PO Box 22490, Riyadh 11426, Saudi Arabia; knawyb@ngha.med.sa

Received 12 July 2018 Revised 14 September 2018 Accepted 20 September 2018 Published Online First 15 December 2018

Check for updates

(C) Author(s) (or their employer(s)) 2019. No commercial re-use. See rights and permissions. Published by BMJ.

To cite: AlKnawy B. BMJ Leader 2018:3:1-5.

\section{ABSTRACT}

When organisations encounter a crisis, the most senior executives are at the spotlight and have responsibility to lead the organisation to safe grounds. This necessitates mental focus to instill confidence and resilience to staff, customers and external stakeholders. In August 2015, a large medical centre in the Saudi Arabia faced a major outbreak with the Middle East Respiratory Syndrome coronavirus (MERS-CoV), and cases accumulated in an unprecedented rate, triggered by a hospital-acquired transmission in the overcrowded Emergency Department. This article summarises the leadership learning from the MERS-CoV outbreak and draws on principles from leadership in extremis studies, a perspective that emphasises specific personality traits, attitudes and styles of individual leaders. It describes phases of the crisis starting with the phase 1 of crisis escalation, which included the emergency response along with measures for building confidence and ending with phase 2 of crisis resolution in which the crisis is used to make permanent and lasting change.

\section{LEADERSHIP RESPONSIBILITIES IN TIMES OF CRISIS}

When organisations encounter a crisis, the most senior executives are at the spotlight. It is the Chief Executive's responsibility to lead the organisation to safe grounds and prevent the system from crumbling. This can be a huge task and tremendous responsibility for the organisation's executive team, which necessitates mental focus to instil confidence and resilience to staff, customers and important external stakeholders. There is likely to be chaos and disturbance in the organisation, with demotivated and confused staff, dissatisfied customers, and negative publicity. It can be demoralising for the organisational leaders, too, seeing their efforts to establish a strong organisation coming to a standstill and wondering whether their capabilities should be called into question.

In August 2015, King Abdulaziz Medical City-Riyadh, Saudi Arabia, one of the largest medical centres in the Middle East, faced its biggest threat ever. Cases of infection with the Middle East respiratory coronavirus (MERS-CoV) started to accumulate in an unprecedented rate in the hospital, triggered by a hospital-acquired transmission in the overcrowded emergency department. The cases appeared to increase day by day; some critically ill patients and some healthcare workers acquired the infection as well. Tensions were running high and fears were rising among the staff and the public. All of a sudden, King Abdulaziz Medical City-Riyadh, a medical flagship institution in Saudi Arabia, came under scrutiny.
The recent MERS-CoV outbreaks in Jeddah, Saudi Arabia in 2014 and in the Republic of Korea in $2015^{1}$ had left etched painful memories. The situation was reminiscent of the devastating 2003 outbreaks of severe acute respiratory syndrome, a disease caused by a closely related coronavirus. It was clear that the situation could get much worse.

At that challenging time and following consultations with my executive team and advisors with expertise on the issue, I made a critical decision, as Chief Executive Officer (CEO), to voluntarily close the hospital. This was a very difficult decision with potential colossal implications from a personal leadership, organisational and political perspective, as the magnitude of the crisis was potentially catastrophic, and the effects and repercussions of the outbreak were felt far and wide by people across the Kingdom of Saudi Arabia. The King Abdulaziz Medical City is a flagship healthcare facility with more than 1000 beds and the largest emergency care centre in the Middle East. It provides healthcare for the Saudi Arabian National Guard Forces, civilian employees and their dependents.

The Medical City also comprises the King Saud Bin Abdulaziz University, which is the training site for a large number of clinical specialties and subspecialties. This distressing and disruptive crisis coincided with the start of the academic year, thus interrupting the education and residence training of more than 3000 students.

Fear and anxiety began to rise throughout the Kingdom as this outbreak coincided with the annual gathering of Hajj, an annual Muslim Pilgrimage. Every year, around two million Muslims from 200 different countries travel to the Kingdom to perform Hajj. Although Hajj takes place in Makkah, in Western Saudi Arabia, transmission of the disease from travels from Riyadh posed a real threat to one of the world's largest mass gatherings.

What follows is a personal reflection from my role as the Chief Executive of King Abdulaziz Medical City on lessons learnt of how leaders should perform in times of health crises or public health crises, or in extremis situations using this fatal infectious outbreak as a reflective case study. The article summarises this experience in a framework to guide leadership action in times of crisis. The framework identifies key roles and critical tasks that leaders need to perform when managing in crises situations (figure 1).

The article draws on principles from leadership in extremis studies, a perspective that emphasises specific personality traits, attitudes and styles of individual leaders, being empirically informed from exemplar leadership cases in the military. ${ }^{2}$ Kolditz $^{2}$ identified a consistent pattern of traits, attitudes and behaviours that characterises successful leadership in dangerous settings. Specifically, he suggests 

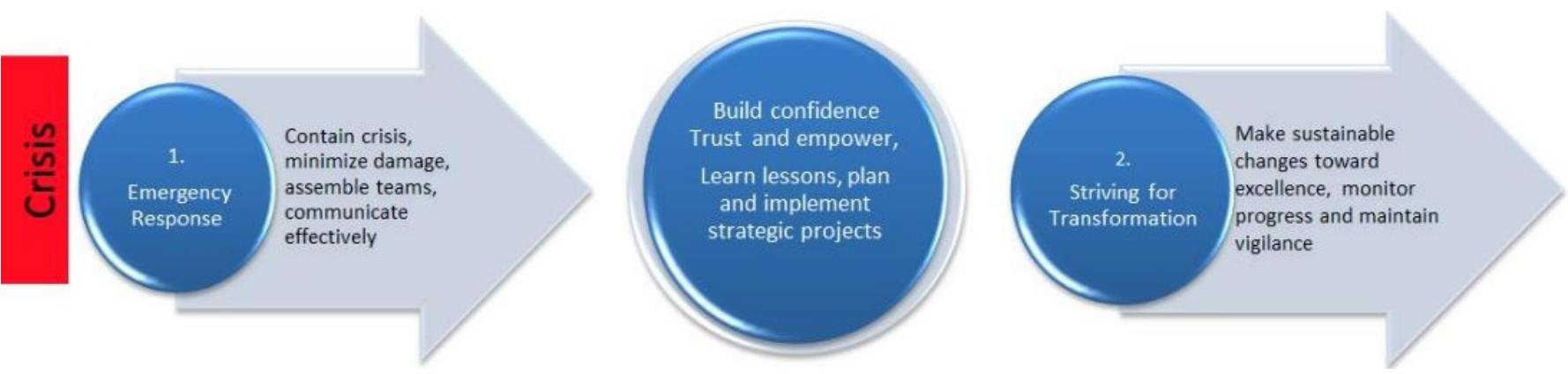

Figure 1 Framework for leadership roles in managing crisis.

that successful in extremis leaders display the following characteristics: (1) they are inherently motivated; (2) they embrace continuous learning; (3) they share risk with their followers; (4) they are not elitist and adopt a lifestyle in common with their followers; and (5) they are highly competent, inspiring trust and loyalty.

The application of this perspective into organisational contexts has been rather limited, although more recently there has been increased emphasis on transferring the principles of the model to diverse organisational and corporate contexts by studying extremis leadership in situ, or in other words leadership in the context of extreme events. ${ }^{3}$ Extreme events present an imminent threat to human life and are either naturally occurring or caused by human action. ${ }^{24}$ This article follows Kolditz's ${ }^{2}$ definition of extremis leadership, according to which leaders provide direction and motivation to followers when there is an actual or perceived risk of physical harm and when members perceive that leadership action has direct influence on their survival of the extreme events. The principles of this perspective underpin the action framework suggested, which summarises the leadership learning from the MERS-CoV outbreak. The actions outlined in table 1 refer to the escalation and resolution phases of the crisis following the occurrence of the incident (ie, the MERS-CoV outbreak) and do not reflect on the preincident warning phase or the long-term recovery time.

\section{PHASE 1: CRISIS ESCALATION}

Emergency response-how can the crisis be contained?

Take decisive actions and calculated risks

Making any decision can be difficult; making critical decisions during a crisis can feel an almost impossible task. Swift action is essential to contain any crisis and its consequences, and a CEO must have the confidence to make a calculated decision, keeping

Table 1 Timeline of events and actions during and in the aftermath of the hospital crisis with the Middle East respiratory coronavirus (MERS-CoV) outbreak in the summer of 2015

\begin{tabular}{|c|c|c|c|}
\hline & Phase & Events & \\
\hline 10-18 August 2015 & Crisis is mounting & & - Cases of MERS-CoV increase in an alarming rate. \\
\hline \multirow[t]{5}{*}{18 August 2015} & \multirow[t]{5}{*}{$\begin{array}{l}\text { Closing the } \\
\text { hospital }\end{array}$} & Hospital closure. & $\begin{array}{l}\text { Closure of the hospital services except chemotherapy and anticoagulation } \\
\text { clinics, haemodialysis unit and intensive care units. } \\
\text { Transfer of non-MERS-CoV patients to other hospitals. } \\
\text { Mobilising medical and nursing teams to manage patients in other hospitals. }\end{array}$ \\
\hline & & Creation of a 'crisis management team'. & $\begin{array}{l}\text { This team functioned as a Command Centre chaired by the medical director to } \\
\text { coordinate the overall response to the emergency. }\end{array}$ \\
\hline & & Internal communication plan. & $\begin{array}{l}\text { Establishment of an internal communication plan to be implemented } \\
\text { throughout the phases of the crisis. } \\
\text { This included using weekly and as-needed email bulletins, posters, an online } \\
\text { portal and frequent site visits by senior management. }\end{array}$ \\
\hline & & External communication plan. & $\begin{array}{l}\text { Establishment of an external communication plan to be implemented } \\
\text { throughout the phases of the crisis. } \\
\text { This plan emphasised a transparent and constructive account of the actions } \\
\text { taken. } \\
\text { - The plan included communication with relevant public healthcare authorities. }\end{array}$ \\
\hline & & Building confidence. & $\begin{array}{l}\text { Thanking the staff. } \\
\text { Seeking out for staff support. } \\
\text { Gathering feedback from staff and patients. }\end{array}$ \\
\hline \multirow[t]{2}{*}{$\begin{array}{l}\text { Starting } 29 \text { September } \\
2015\end{array}$} & \multirow[t]{2}{*}{$\begin{array}{l}\text { Phase 2: crisis } \\
\text { resolution }\end{array}$} & Reopening the hospital. & $\begin{array}{l}\text { Reopening of outpatient clinics on } 29 \text { September } 2015 . \\
\text { Reopening of inpatient wards on } 4 \text { October } 2015 .\end{array}$ \\
\hline & & Establishing a transformation plan. & $\begin{array}{l}\text { Creating urgency for transformation. } \\
\text { Engaging the middle management. } \\
\text { Overcoming resistance to change. } \\
\text { No time to relax. }\end{array}$ \\
\hline
\end{tabular}


in mind that it might not be the 'best' decision as seen by various constituents. A leader must be decisive in difficult times.

After the infection outbreak at our hospital, the executive team consulted the appropriate committees and boards and, taking a calculated risk to declare a major incident, we voluntarily closed the hospital services on 18 August 2015. The rationale for hospital closure was to stop further transmission among patients, visitors and healthcare workers. The chemotherapy and anticoagulation clinics, haemodialysis unit and intensive care units were left open. We judged that closure of those critical units would have been more detrimental to patients' well-being. Closing the hospital was a radical measure and entailed high risk because of the impact on our patients and the wider community, but it was deemed necessary to contain the outbreak. At the same time, the importance of managing the impact of the hospital closure was made clear to our senior staff, ensuring that they diverted non-MERS-CoV patients to other hospitals where necessary. An agreement was made with nearby hospitals to accept our non-MERS-CoV patients-to minimise disruption to their care, also minimising damage to the hospital due to potential risk for litigation and similar legal implications.

\section{Think creatively and simply in the face of overwhelming detail}

In a crisis, it is natural that people get mired in detail and complexity when debating solutions. As a leader, while it is one's role to understand the critical details from various aspects, it is more important to help the team see the wider perspective. One must not be tempted to get drowned in small details, but they should instead 'think about the bigger picture'. There is widespread agreement among scholars that leaders in times of crisis should only concern themselves with strategic issues, avoiding to get entangled in operational decision making. ${ }^{5}$ As the decision for hospital closure was taken, there was much debate among our senior managers about how best to mitigate the patient backlog of the ambulatory care clinics; many suggestions were put forward, increasing in complexity. However, a simple, effective solution that had not been considered in the midst of the detail was to simply extend the working hours of the ambulatory care clinics once reopened for a short time. As a leader, one should aim to overcome the disruptive noise of a crisis with creative thinking.

\section{Conveying a clear message and ensuring visible senior leadership} during the crisis

Ensuring the visibility of all senior staff is essential during a crisis. While the CEO is ultimately accountable for conveying a clear message for strategic action during a crisis, they must also ensure that senior and middle management play their role in communicating clear and consistent messages on operational action, to instil confidence and to show that the situation is under control. The CEO and the managers therefore have a responsibility to explain the action taken during the crisis, and the reason why such action was deemed essential. They should explain what worked and what went wrong during a crisis to help restore trust in the organisation. We established a 'crisis management team' in the form of a Command Centre chaired by the medical director. $\mathrm{My}$ role as the CEO was to provide support, resolve differences, ensure strategic focus and make the difficult decisions, while my management staff led and communicated the day-to-day crisis resolution. The Command Centre had a permanent base during the crisis and was responsible for coordinating the overall response to the emergency. The Centre clarified priorities for action and provided coherence in the actions undertaken by the various hospital departments and ensure consistency in the messages communicated to all staff.

\section{Seek outside expertise if necessary}

Part of the role of the CEO is to listen, study and solicit opinion. Views within the organisation are essential, but should not prevent the leader from looking and learning from outsiders. During the crisis at our hospital, connecting with external local and international healthcare organisations with experience in crisis management and transformation to learn from their expertise was essential.

\section{Communicate actions internally and externally}

Clear communication with staff and customers should be 'a business as usual' for any organisation, but in the event of a crisis it becomes paramount. The CEO should provide timely updates on the crisis within the organisation, along with clear protocols for action throughout the phases of the crisis. At our hospital, we used multiple channels of communication. Weekly and as-needed email bulletins were regularly published for our staff with updates and guidance (eg, the expectation and necessity to undergo infection control training), posters were displayed in all buildings, an online portal was established allowing staff to ask questions, while senior management undertook frequent site visits to constantly update front-line staff.

Communication outside the organisation should aim to present a transparent and constructive account of the actions taken and to proactively manage the impact of the crisis on the wider community and address issues linked to the inherent politicisation of a crisis. For example, we ensured that all relevant public healthcare authorities were kept informed of the infection situation as it evolved and convened ministerial-level meetings to keep discussions open and politicians engaged. This ensured that the important stakeholders were involved during the early crucial stages of crisis escalation. Involving public health authorities and politicians early on offered critical intelligence to provide a strong response and enhanced confidence in our external constituents that our organisation was responsive and transparent.

Finally, but not less importantly, drawing a communications plan was essential to signal to the media and the public that the crisis was being addressed properly, explaining actions taken and what was achieved. This was crucial, as the reputation of an organisation and people's trust in it takes time to rebuild. One of the first actions we took after establishing a management crisis leadership team was to establish a call centre for patientsinforming them of the developing situation and providing practical advice for what they should do during the crisis. Not only did this ensure that patients and the public were kept informed, but also expedited recovery via enabling the rebooking of patient appointments in a timely fashion.

\section{Building confidence-how can I de-escalate the crisis and restore operations?}

Can we thank the staff enough?

I made it my responsibility to personally thank all members of the staff-rather than just relying on cascading down a typical and generic 'thank you' message seen to be coming 'from on high'. This approach was successful; I received many messages of support from my team, at all levels, and often these were as simple as an email reassuring me that I was not alone. These messages conveyed a strong desire to be part of the movement to resolve the crisis-something that any leader should seize as 
a golden opportunity, especially in difficult times. This overwhelming support buoyed morale and ensured that we were all working together as one team, towards achieving a common goal. Indeed, the crisis in many ways had the effect of strengthening relationships within the organisation.

Clearly it is not enough to keep the staff informed-their efforts should be acknowledged by leaders who should thank them explicitly for what they achieved; thank individual staff, teams and units. Express understanding at the difficult situation they find themselves in; acknowledge the disruption this has caused them; and above all, show gratitude for their continued support. Staff should feel valued and protected by their leader, and they should feel that their safety is a priority for the organisation. It is important to anticipate that morale could be low and to act swiftly to convey calming and reassuring messages. Through these actions, the leader demonstrates to staff that he is one of them and he is there for them.

\section{Seek out for support and don't get isolated}

A crisis can demoralise, demotivate and instil fear in people, and leaders are not immune to these feelings. However, it is essential for leaders to remember their role and not to crumble from within. This is of course easier said than done, but it is important to keep the critical issues in perspective and use the support of one's team. During the outbreak, we held daily meetings with the 'crisis management team' to get situational reports. Some days, the outlook appeared bleak, especially in the face of reports that front-line staff members had become infected. It would have been easy for me as a leader to lose heart, but I took care not to go into isolation and recognised that I needed to provide leadership and work with our staff to devise solutions to the crisis.

\section{Gather feedback from staff and patients to learn lessons}

It seems obvious, but it is crucial to learn and implement lessons from any crisis. Too many leaders experience a crisis in their organisations; resolve it somehow, before simply returning to 'business as usual'. They may be missing a real opportunity to make long-lasting changes. Do not miss a good crisis. It is essential to be open and transparent with all staff, to solicit their views and gain an indepth understanding of what should be changed. Ask whether anything could have been done better or earlier. As the crisis was being resolved at our hospital, we realised the importance of tapping into our most precious knowledge base: our staff. I gave presentations to gather feedback as well as convey messages; convened several workshops with representation from all hospital departments for sharing thoughts, challenges and solutions; disseminated a 'how can we change?' survey for completion by all staff; and established a dedicated portal and email address for the dissemination of ideas. These actions and the involvement of all staff clearly differentiated scientific, data-driven professional advice from the anecdotal, hesitant stories which are the enemy of change. Feedback from staff during these presentations provided important suggestions regarding patient flow and how to enhance compliance with infection control practices.

The customer is also a crucial source for learning and knowledgeable input. Without engaging them trust will also be harder to rebuild.

Much has been written of the 'organizational apology' as an important step in crisis management. We believe it is crucial to apologise swiftly during crisis: to patients and their families who were infected or whose care the outbreak was interrupted, to the employees for the interruption to their work, and in the worse cases to those employees who were infected.

\section{PHASE 2: CRISIS RESOLUTION}

Striving for improvement-how can one seize the opportunity to make permanent and lasting change?

Commit to system transformation and promote it

It is often the case that a crisis exposes inadequate systems and structures in an organisation. A crisis, once overcome, provides a real opportunity for a CEO to reflect on the overall system and whether it is fit for the future. Therefore, once lessons are learnt, transformational change is needed to improve productivity and efficiency - and should be relished. This crisis revealed the urgent need to address issues of overcrowding in the emergency department, compliance with infection control practices and with timeliness of triaging and proper isolation of patients with suspected MERS-CoV infection.

System change should not add new layers; it should simplify and clarify structures and the CEO should present a clear rationale behind the transformation. In our situation, it was clear that the system needed some redesign. The key message for transforming our organisation was to achieve 'basic, safe, reliable care', and this message was essential to regain the trust of the staff, patients and the public. We consistently stressed the potential for improvement stemming from the change.

\section{Ensure senior and middle management cooperation to overcome} resistance to change

While some staff will relish change, others will be more cautious. In discussions with their CEO, senior staff can amplify risks, be overcautious, or highlight remote and unlikely possibilities often without relying on any data or evidence. Such staff attitudes can be obstructive to change and disruptive to the aimed system transformation. Resistance in our case stemmed from various sources: some staff were unwilling to go outside their comfort zone, or unable to understand the magnitude of the crisis; others were fearful that the change required was above their leadership capabilities; or they felt that change would threaten their position in the management structure and that they would be undermined in front of the staff as they did not come up with the initiatives. Few even felt that their area had not been the cause of the problem, and therefore they were performing effectively, often stating: "my department is better than the others - we don't need to change."

\section{Don't surround yourself with consenting voices}

Successful leaders should not surround themselves with consenting voices only, as different perspectives are crucial. It is the role of the CEO to remove any obstacles and overcome hesitancy to disclose concerns. This is not easy in a highly hierarchical culture. In our situation, once the board made the decision to transform, it was my responsibility to communicate this decision to all staff and stakeholders and persuade them. A CEO needs to trust their team, listening candidly to their concerns and developing their confidence. They must find strong team members who are multitalented and supportive and do not shy away from challenges; identify these as 'good soldiers' who will strive and shine in the event of a crisis and who will rally behind the system and its leadership.

\section{And finally, no time to relax}

Speed is important: time can erode into the organisation's desire to make changes, especially if the immediate crisis is over. A crisis, once resolved in the immediate term, provides a unique sense 
of urgency to accelerate change. It is important to maintain the momentum of the implemented transformation for the good of the organisation. Of course, true transformation is complex and takes time and this is just the beginning of a long journey, but if you have put in place the fundamentals, you will be off to an excellent start. Although transformation has addressed the root causes of the MERS-CoV infection outbreak, maintaining high level of vigilance is crucial. MERS-CoV continues to be an important public health threat as cases are still occurring in Saudi Arabia and abroad. ${ }^{6-9}$

I believe that the response to our crisis exemplified what Kolditz identified as traits, attitudes and behaviours that characterise successful leadership in dangerous settings. ${ }^{1}$ Of course, it is not up to the author in this perspective to judge his own actions as being competent or not. However, the CEO has built on inherent motivation, continuous learning, sharing risk with followers and inspiration of trust and loyalty in overcoming this major crisis.

Acknowledgements Words are truly not enough to express my sincere admiration for and gratitude to all of our staff, managers, chairmen of the departments and executive team, for their unwavering support through one of the most challenging and serious crises in the history of our organization.

Contributors This is a personal reflection from the corresponding author as a healthcare CEO in a major healthcare disaster. He is responsible for the overal content of this article.
Funding The authors have not declared a specific grant for this research from any funding agency in the public, commercial or not-for-profit sectors.

Competing interests None declared.

Patient consent Not required.

Provenance and peer review Not commissioned; externally peer reviewed.

\section{REFERENCES}

1 Arabi YM, Balkhy HH, Hayden FG, et al. Middle east respiratory syndrome. N Engl J Med 2017:376:584-94.

2 Kolditz TA. In extremis leadership. 1st edn. San Francisco: Jossey-Bass, 2007.

3 Hannah ST, Uhl-Bien M, Avolio BJ, et al. A framework for examining leadership in extreme contexts. Leadersh Q 2009;20:897-919.

4 Hannah ST, Campbell DJ, Matthews MD. Advancing a research agenda for leadership in dangerous contexts. Military Psychology 2010;22(sup 1):S157-S189.

5 Boin A, Hart Paul 't, Stern E. The politics of crisis management: public leadership under pressure. New York: Cambridge University Press, 2005.

6 Ministry of Health, 2018. National events - epi-weeks of 2018. https://www.moh.gov. sa/en/CCC/events/national/Pages/2018.aspx (accessed 4 Sep 2018).

7 GOV.UK, 2018. MERS-CoV case in England. https://www.gov.uk/government/news/ mers-cov-case-in-england (accessed 4 Sep 2018).

8 The Telegraph, 2018. Passengers on flight from Middle East sought after patient diagnosed with deadly camel flu in Leeds. https://www.telegraph.co.uk/news/2018/ 08/23/patient-diagnosed-deadly-mers-virus-leeds-fellow-passengers/ (accessed 4 Sep 2018).

9 Reuters, 2018. South Korean man infected by MERS virus, first case in 3 years. https:// www.reuters.com/article/us-southkorea-health-mers/south-korean-man-infected-bymers-virus-first-case-in-3-years/ (accessed 8 Sep 2018). 